electrocardiogram was fortuitously taken at the onset of one such VT-induced cardiac arrest (Figure 1). The first portion of the electrocardiogram shows a sinus tachycardia (with low-amplitude $\mathrm{P}$ waves) and first-degree heart block. Undersensing of the intrinsic QRS complex is also noted, leading to inappropriate pacing immediately after the unsensed QRS complex (Figure 1, black arrows). "Loss of capture" is seen but actually represents attempted pacing in the ventricular refractory period caused by lack of appropriate sensing. The final "normal" QRS complex is undersensed, and a pacing output is delivered at the apex of the $T$ wave ( $R$ on $T$ phenomenon; Figure 1, asterisk) inducing monomorphic VT.

The problem was temporarily remedied by increasing pacemaker sensitivity from 2 to $0.5 \mathrm{mV}$ (reducing the sensing voltage), allowing the temporary pacemaker to "see" the intrinsic QRS complexes better. Because of the clear restoration of an appropriate underlying rhythm, definitive treatment was to switch off and remove the malfunctioning epicardial system. No further VT was observed, and antiarrhythmic medication was discontinued.

\section{DISCUSSION}

Although initial implant pacing parameters can be satisfactory, vigilance must be observed for the development of temporary pacing malfunction. In this case the problem was not loss of capture but undersensing of the intrinsic $\mathrm{R}$ wave, leading to inappropriate delivery of a pacing spike on the $T$ wave.
The consequence of both undersensing and oversensing can be catastrophic. In our case undersensing and inappropriate pacing led to a malignant ventricular arrhythmia and cardiac arrest. Equally, oversensing (mistaken recognition of intrinsic cardiac activity) can lead to pacing inhibition and, in the case of the patient with no underlying rhythm, asystolic cardiac arrest. Suspicions of undersensing should be raised when pacing spikes appear within the QRS or T wave and those of oversensing when pacing spikes do not appear when they should during prolonged pauses or periods of asystole. However, true loss of capture occurs when an appropriately timed pacing spike does not produce a QRS complex at all.

Assessing pacemaker sensitivity is often difficult because most temporary systems do not have the inbuilt functionality to measure a patient's intrinsic $\mathrm{R}$ wave, as seen through the pacing leads. One method is to turn the pacing rate low enough to allow intrinsic QRS complexes to predominate. During a steady period of intrinsic ventricular activity (as noted usually by a "V sense" flashing LED on the generator), one increases the sensitivity voltage setting until the system no longer records "V sense," but a "V pace" event occurs. This voltage is roughly the maximum amplitude of the intrinsic $\mathrm{R}$ wave that is seen by the pacing system, and a sufficient margin should be set to avoid oversensing or undersensing issues based on this voltage. If doubt or malfunction still exists, then early collaboration with the electrophysiology team is recommended.

\title{
Gastroaortic fistula: A rare and lethal complication of esophageal stenting after esophagectomy
}

\author{
Daniel Whitelocke, BSHon, Michael Maddaus, MD, Rafael Andrade, MD, and Jonathan D'Cunha, MD, \\ $\mathrm{PhD}$, Minneapolis, Minn
}

The use of esophageal stenting for postesophagectomy leak is increasing, with acceptable clinical results. ${ }^{1}$ Gastroaortic fistula is a potential highly lethal complication of stenting. To increase awareness of this potential complication, we present a case of postesophagectomy gastroaortic fistula after esophageal stenting.

\footnotetext{
From the Division of Thoracic and Foregut Surgery, Department of Surgery, University of Minnesota, Minneapolis, Minn.

Disclosures: None.

Received for publication March 9, 2010; accepted for publication March 26, 2010; available ahead of print May 10, 2010.

Address for reprints: Daniel Whitelocke, BSHon, Meharry Medical College, 515 Basswood Ave, S-163, Nashville, TN 37209 (E-mail: daniel_whitelocke@rogers.com). J Thorac Cardiovasc Surg 2010;140:e49-50

0022-5223/\$36.00

Copyright (c) 2010 by The American Association for Thoracic Surgery doi:10.1016/j.jtcvs.2010.03.042
}

\section{CLINICAL SUMMARY}

A 53-year-old woman underwent an esophagectomy for T3 adenocarcinoma involving the gastroesophageal junction through a left thoracoabdominal approach with her anastomosis in the left chest at $35 \mathrm{~cm}$. She had an anastomotic leak on postoperative day 6 , and this was managed nonoperatively. Unfortunately, her clinical status worsened, and she was referred at 3 weeks postoperatively for intervention. Additional past medical history was also significant for chronic obstructive pulmonary disease, hypertension, anemia, and morbid obesity. She was quite debilitated on arrival in referral with systemic signs of infection.

The patient underwent esophagogastroduodenoscopy and placement of a Polyflex esophageal stent (Boston Scientific, Natick, Mass). Right video-assisted thoracoscopic surgical 
drainage of her thoracic cavity was performed because of empyema at the time of referral. The left-chest anastomosis appeared well drained by means of computed tomographic analysis, and contrast study showed no evidence of ongoing leak and a well-positioned stent. ${ }^{2}$ The patient was followed closely in the hospital and maintained on intravenous antibiotics. Nutritional support was through a jejunostomy feeding tube. The esophageal stent was removed at 4 weeks after esophagectomy and replaced because the defect appeared to be healing well. The patient continued her slow improvement, and then at 6 weeks after esophagectomy, she had abrupt onset of massive gastrointestinal bleeding and hematemesis with hemodynamic compromise. ${ }^{3}$ She underwent esophagogastroduodenoscopy in the operating room, which demonstrated a gastroaortic fistula on removal of the stent. An emergency thoracotomy was performed with primary repair of the aorta and esophageal diversion with cervical esophagostomy. ${ }^{4}$ She had a difficult postoperative course and died 2 weeks later from multisystem organ failure.

\section{DISCUSSION}

Our group has had an extensive experience with esophageal stenting for leaks and perforations. This patient came to us septic and debilitated from an uncontrolled postesophagectomy leak that had been present for about 3 weeks. As part of our standard approach, we placed an esophageal stent to exclude the leak and then drained the active infection by means of thoracoscopy. This is the only patient we have treated using this algorithm who has had a left thoracoabdominal approach for resection. The proximity of the aorta and resultant infection are clearly concerns for this approach in retrospect. Although the stent was positioned well and the patient was recovering acceptably from her septic insult, the residual infection around the aorta and the spatial relationship of the stent to the aorta led to clear erosion of the distal aspect of the stent through the proximal stomach and into the aorta.

In the patient with a leak who is seen after esophagectomy, the complication of gastroaortic fistula has not been reported previously. This case represents one of the first reports of this complication related to the use of esophageal stents ${ }^{5}$ and should raise concerns regarding esophageal stenting for leak after a left thoracoabdominal approach for esophagectomy because of anatomic considerations. ${ }^{4}$ There is little doubt that the periaortic infection from the leak contributed substantially to the eventual development of the gastroaortic fistula. As esophageal stents become used more widely and with increasing frequency, one should be cautioned regarding this potential complication.

\section{References}

1. Freeman RK, Ascioti AJ, Wozniak TC. Postoperative leak management with the Polyflex esophageal stent. J Thorac Cardiovascular Surg. 2007;133:333-8.

2. Korst RJ, Port JL, Lee PC, Altorki NK. Intrathoracic manifestations of cervical anastomotic leaks after transthoracic esophagectomy for carcinoma. Ann Thorac Surg. 2005;80:1185-90.

3. Tak AM, Klizek RD, Campion JP. Primary aorto-esophageal fistula: a rare cause of gastrointestinal hemorrhage. Internet Journal of Internal Medicine. 2005. Available at: http://www.ispub.com/.../primary_aorto_esophageal_fistula_a_rare_ cause_of_gastrointestinal_hemorrhage.html. Accessed March 16, 2009.

4. Unosawa S, Hata M, Sezai A, Niino T, Yoda M, Shimura K, et al. Surgical treatment of an aortoesophageal fistula caused by stent implantation for esophageal stenosis: report of a case. Surg Today. 2008;38:62-4.

5. Chandrashekar G, Kumar VM, Kumar AK. Repair of aortoesophageal fistula due to a penetrating atherosclerotic ulcer of the descending thoracic aorta and literature review. J Cardiothorac Surg. 2007;2:12.

\title{
Giant mycotic pseudoaneurysm of the left main coronary artery after pneumococcal pneumonia
}

\author{
Dimitri Kalavrouziotis, MD, and François Dagenais, MD, Sainte-Foy, Québec, Canada
}

\footnotetext{
From the Department of Cardiac Surgery, Institut Universitaire de Cardiologie et de Pneumologie, Sainte-Foy, Québec, Canada.

Disclosures: None.

Received for publication Nov 14, 2009; accepted for publication Nov 22, 2009; available ahead of print March 17, 2010.

Address for reprints: Francois Dagenais, MD, Laval Hospital, Department of Cardiac Surgery, 2725 chemin Sainte-Foy, Québec, Québec G1V 4G5, Canada (E-mail: francois.dagenais@chg.ulaval.ca).

J Thorac Cardiovasc Surg 2010;140:e50-2 $0022-5223 / \$ 36.00$

Copyright $\Subset 2010$ Published by Elsevier Inc. on behalf of The American Association for Thoracic Surgery

doi:10.1016/j.jtcvs.2009.11.054
}

Coronary artery aneurysms are mainly atherosclerotic in origin. ${ }^{1}$ Conversely, mycotic coronary artery aneurysms are extremely uncommon. We describe a unique case of mycotic pseudoaneurysm of the left main coronary artery after pneumococcal pneumonia.

\section{CLINICAL SUMMARY}

A 62-year-old man without a history of cardiac disease had chest discomfort of 3 weeks' duration. The chest pain was exertional but also varied with the patient's position. 